\title{
O ENTRELAÇAMENTO ENTRE O POLÍTICO, O JURÍDICO E A ÉTICA NO DISCURSO DO/SOBRE O MST: UMA QUESTÃO DE LUGAR-FRONTEIRA
}

Freda Indursky*

\begin{abstract}
RESUMO: Este trabalho, inscrito no marco teórico da Análise do Discurso da Escola Francesa, examina o discurso sobre e do MST. Nesse trabalho as análises são produzidas a partir de reportagens publicadas na Folha de São Paulo (1995 - 1996). Nele, são analisadas as diferentes designaçōes por que passa o processo de luta pela posse da terra no Brasil, as quais são indicadoras dos lugares sociais que os diferentes sujeitos discursivos ocupam na ordem social brasileira. Constatou-se que a designaçāo ocupação, que remete à posição-sujeito do trabalhador rural sem-terra, apóia-se no "direito de propriedade", enquanto a designação invasão, que refere a posição-sujeito do proprietário da terra, acenta-se no "dircito à propriedade". Essas designações mostram esse confronto de discursos, que é examinado no ponto nodal em que se entrecruzam o politico, o juridico e a ética, que constitui o lugar-fronteira discursivo em pauta.
\end{abstract}

PALAVRAS-CHAVE: Ocupação; invasão; direito de propriedade; direito à propriedade; ética conservadora; ética social.

Enquanto a terra não for tornada um

bem público e não privado, o Brasil

* Universidade Federal do Rio Grande do Sul - UFRGS. 
vai se tornar um grande acampamento Herbert de Souza ${ }^{1}$

\section{Introduzindo a questão}

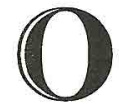

Movimento dos Trabalhadores Rurais sem Terra (MST), fundado em 1984, vem ocupar um lugar importante no cenário politico brasileiro, tendo como objetivo lutar pela redistribuição das terras no Brasil. Na verdade, o MST é responsável pela reintrodução da Reforma Agrária na agenda política do País.

O surgimento do movimento dos trabalhadores rurais sem terra no Brasil desencadeou uma discussão sobre os lugares políticos já consolidados e dotados de legalidade no espaço público. Lugares como propriedade rural e latifúndio encontram abrigo no discurso político e jurídico sobre o direito de propriedade da terra, os quais remetem, por sua vez, a sujeitos legitimamente inscritos no espaço público tais como proprietários rurais, latifundiários, fazendeiros.

Esse fato se dá em contraposição a um não-lugar e remete àqueles que não encontram para si um espaço entre os lugares políticos já existentes, inscrevendo-se, pois, em sua origem, entre os excluídos da ordem social, política e jurídica brasileiras bem como do discurso político e jurídico sobre a propriedade rural.

Esse movimento, pois, ao autodesignar-se de movimento dos trabalhadores sem terra, desencadeou um processo de designação - sem-terra - que constrói discursivamente, um novo sujeito político no espaço público brasileiro, o qual passa a falar em nome de um determinado segmento dos excluídos do cenário político brasileiro (Indursky, 2000). Vale dizer: ao lado dos proprietários rurais, dos latifundiários e dos fazendeiros encontram-se agora os sem-terra,

1 A epigrafe que abre este texto foi extraída de uma entrevista concedida por Herbert de Souza, o saudoso sociólogo Betinho, à Folha de São Paulo, em 17.8.95. 
que representam um novo sujeito politico, tal como o concebe Jacques Rancière: “[...] são os 'sujeitos do dissenso', aqueles que tomam a palavra quando e onde não deviam fazê-lo e apenas são sujeitos políticos quando o fazem" (Rancière, F.S.P., ${ }^{2}$ 10.9.95, p. 5-10).

O encontro destes dois sujeitos antagônicos, aquele que desde sempre teve direito de falar sobre a questão da terra e a dela considerar-se proprietário, portanto um sujeito de direito, e o que surge do não-lugar, de dentre os excluídos, o sem-terra, e passa a falar de seu "direito à terra", se dá em um lugar-fronteira em que o jurídico passa a ser questionado por uma interpretação ética de cunho conservador, pelo primeiro, e de natureza social, pelo segundo. Ou seja, tais sujeitos só podem instituir-se em Formações Discursivas antagônicas e só se encontram nesse lugar-fronteira. Fora dele, não há possibilidade de interlocução e, dentro dele, a interlocução é atravessada pelo dissenso, pelo desintendimento, pelo estranhamento, pela repúdia, pelo não reconhecimento dos direitos mútuos e das interpretações de ambas as partes em litígio. Para tentar entender um pouco mais este lugar-fronteira, cito novamente Rancière. Este autor, para explicar o que seja politica, afirma que

política é antes de mais nada o conflito sobre a existência de uma cena comum, sobre a existência e a qualidade daqueles que nela se fazem presentes. É necessário inicialmente estabelecer que a cena existe para o uso de um interlocutor que não a vê e que não tem razão alguma para vê-la, pois ela não existe (Rancière, 1995: 49) ${ }^{3}$

2 F.S.P. é a sigla que será utilizada para referir abreviadamente à Folha de S. Paulo.

3 A tradução é minha. Transcrevo, a seguir, o texto original: "La politique est d'abord le conflit sur l'existênce d'une scène commune, sur l'existence et la qualité de ceux qui y sont présents. Il faut d'abord établir que la scène existe à l'usage d'un interlocuteur qui ne la voit pas et qui n'a pas de raisons de la voir puisqu'elle n'existe pas". 
INDURSKY, Freda. O entrelaçamento entre o político, o jurídico e a ética no discurso...

A partir da reflexão de Rancière, percebe-se que o grande problema que se estabelece no cenário político brasileiro, no que concerne o litígio que envolve proprietários rurais, de um lado, e os sem-terra, de outro, consiste no fato de que os primeiros não reconhecem a existência dos segundos como seus interlocutores e não o fazem por não entendê-los qualificados para o diálogo. E, se não os reconhecem, a cena discursiva ${ }^{4}$ de interlocução não se constitui. Em função disso é que se estabelece o que estou designando de lugar-fronteira. Este certamente não corresponde a uma cena de interlocução, que é própria de interlocutores que se reconhecem como tal. Ao contrário. O lugar-fronteira corresponde a uma zona de "interincompreensão constitutiva" (Maingueneau, 1989: 119-20) $\mathrm{e}$, por conseguinte, mútua, que se constrói sobre o desentendimento e que explica o litígio que se mantém entre ambas as partes que não se reconhecem como interlocutores.

Em função dessa ausência de uma cena de legítima interlocução, os sem-terra traçaram uma estratégia política que visa conquistar seu acesso à terra. Para tanto, mobilizam uma prática política, que desencadeia, por sua vez, uma prática discursiva que põe constantemente a reforma agrária na ordem do dia do discurso social brasileiro, questionando a eficácia da ação governamental e sua vontade política de efetivamente redistribuir as terras no Brasil e polemizando o discurso jurídico brasileiro sobre a questão da propriedade. Podemos chamar estas práticas do MST de atividade política que, segundo Rancière,

desloca um corpo do lugar que lhe havia sido atribuído ou troca a destinação de um lugar; ele faz ver o que não tinha

4 Em meu livro $A$ fala dos quartéis e as outras vozes (1997) trabalhei com a noção de cena discursiva que não se confunde com cena enunciativa, por ser dotada de invisibilidade; não recortando um espaço claro e delimitado para seus participantes; ela pode mobilizar vários interlocutores, muitos dos quais sem transparência alguma. 
espaço para ser visto, faz ouvir um discurso onde apenas havia ruido anteriormente (Rancière, 1995: 53) ${ }^{5}$

Certamente as práticas discursivas e não-discursivas do MST podem ser entendidas como atividades politicas, pois dão ao movimento visibilidade e os discursos que provocam possibilitam a lisibilidade de seus reclamos. Isso não significa fidelidade quanto aos sentidos que circulam, mas este novo sujeito político adquire a capacidade de produzir cenas polêmicas, demandas e discursos em confronto que fazem ver a contradição dos dois sujeitos em conflito e suas lógicas em colisão.

Tal fato gera uma relação de discursos em tensão, dentre os quais destaco o discurso dos proprietários rurais e o discurso dos sem-terra. Esses discursos são produzidos de lugares políticos diferentes, produzindo um espaço discursivo marcado pelo antagonismo de Formações Discursivas em confronto. E, na ausência de uma cena discursiva de interlocução, esses discursos podem ser apreendidos pelo viés das narrativas da imprensa. É ela que dá maior ou menor visibilidade ao movimento, maior ou menor fidelidade a suas demandas. Esta é a razão pela qual trabalho com o discurso que a mídia produz sobre este litigio.

É no âmbito dessa confluência de discursos em tensão, nesse lugar-fronteira, que o presente trabalho encontra seu propósito, pois proponho-me a analisar, pelo viés do processo de designação que a tomada da terra ai desencadeia, o político e o juridico que perpassam essa rede de formulações discursivas e suas implicações éticas. Como se vê, a própria reflexão que pretendo realizar nesse trabalho só pode ocorrer porque, de fato, estes discursos se encontram nesse lugar-fronteira.

5 O destaque e a tradução são meus. A seguir, cito o trecho original "L'activité politique est celle qui déplace un corps du lieu qui lui était assigné où change la destination d'un lieu; elle fait voir ce qui n'avait pas lieu d'être vu, fait entendre comme discours ce qui n'était entendu que comme bruit". 
INDURSKY, Freda. O entrelaçamento entre o político, o jurídico e a ética no discurso...

\section{O político, o jurídico e a ética}

Antes de passar às análises propriamente ditas, porém, desejo refletir um pouco sobre as três noções que estão mobilizadas e entrelaçadas nesse trabalho.

Inicialmente, é preciso distinguir o político da política. Há uma tendência em confundir estas duas noções, o que não ajuda a refletir teoricamente. Diria, acompanhando Rancière, que a política, de um modo geral, pode ser entendida como um conjunto de

processos através dos quais se operam a agregação e o consentimento das coletividades, a organização dos poderes, a distribuição dos lugares e funções e os sistemas de legitimação desta distribuição (Rancière, 1995: 51)

Já para Corten (1999: 37), a politica é a área funcional especializada, na qual, por meio das instituições políticas, se realizam as atividades políticas.

Para nosso trabalho, não é a politica, tal como proposta acima, que vai interessar. Para nossa reflexão, o que vai ser mobilizado é o político. Ainda, segundo Corten (idem, ibidem), o politico "é, de fato, em si mesmo, uma representação". E o autor continua afirmando que por "representação do político" entende a "cena onde os elementos que perpassam a sociedade são vistos como 'forças' e vistos como forças políticas" (idem, ibidem). Ao que desejo acrescentar: a cena discursiva é lugar de tensão. É espaço de confronto. $\mathrm{E}$, como vimos na seção anterior, no caso do discurso do/sobre os sem-terra, a cena discursiva possivel consiste em um lugar-fronteira, em que se defrontam os sujeitos históricos desse litígio.

6 A tradução é minha. Refiro, a seguir, o texto original: "on appelle généralement du nom de politique l'ensemble des processus par lesquels s'opèrent l'agrégation et le consentement des collectivités, l'organisation des pouvoirs, la distribution des places et fonctions et les systèmes de légitimation de cette distribution". 
Em meu entender, o politico se constrói por meio dos discursos em circulação no discurso social. ${ }^{7} \mathrm{Ou}$ seja, o político é resultado da trama de diferentes processos discursivos atravessados pelo interdiscurso e recortados por diferentes formações discursivas. $\mathrm{Ou}$ seja, para a análise do discurso, o que conta não é a política, mas o político. Ainda citando Corten, fazemos uma nova distinção que se impõe para nosso trabalho:

o político [...] não corresponde ao discurso político [...] De um lado, o político não se limita ao campo do discurso político mas, de outro, não se estende a toda tela discursiva como multiplicidade imanente de relações de poder. ${ }^{8}$ (Corten, 1999: 38)

Ou seja, não se trata de afastar/negar o discurso político, mas o que nos mobiliza, nos discursos políticos, é o politico que, por meio deles, podemos captar e analisar. E mais: no âmbito do presente trabalho, procuramos o político pelo viés do discurso político veiculado pela mídia. Vale dizer: o politico tampouco se confunde com o jornalismo politico. O político é, pois, trabalho de construção discursiva do social.

Interessa também, no âmbito desse trabalho, deixar claro o que entendo como jurídico. Também aqui não ocorre superposição entre o discurso jurídico e o jurídico. Na minha concepção, o discurso jurídico é construído pelo conjunto de textos jurídicos que estabelecem a legislação de um país, por meio da qual a sociedade é ordenada. Ou seja, o discurso jurídico é assunto de especialistas: juristas, juizes, legisladores etc.

Enquanto que o juridico é resultado do trabalho de construção discursiva, instaurado na cena discursiva, pelos diferentes sujei-

7 Entendo como discurso social o conjunto de discursos dispersos que se encontram em circulação e não apenas aqueles discursos que identificam o discurso hegemônico de uma sociedade, como faz Marc Angenot.

8 Os destaques são meus. 
INDURSKY, Freda. O entrelaçamento entre o político, o jurídico e a ética no discurso...

tos históricos que nela se confrontam, pelo viés dos discursos em circulação no discurso social. Ou seja, não se trata de afastar/ negar o discurso jurídico, mas de captar os diferentes gestos de interpretação que a partir dele se produzem. Estes gestos de interpretação do texto legal, instaurados por sujeitos não-especialistas, tecem processos discursivos que vêem afetados pelo interdiscurso e que também podem ser recortados por diferentes formações discursivas. É sobre estes processos discursivos, apreendidos no discurso da imprensa, que vamos nos inclinar para examinar o jurídico que se inscreve nos discursos da/sobre a questão da terra.

É evidente que o político e o juridico não se encontram separadamente, ao contrário do discurso político e do discurso jurídico. Político e jurídico convivem de forma imbricada nos discursos em circulação, de um modo geral, e, por conseguinte, no discurso da mídia, de modo particular, que é o que interessa no trabalho em tela. Não só estes discursos se superpõem como há algo que promove esse entrelaçamento. Refiro-me à ética. É a ética que estabelece o amálgama do politico com o juridico. Vejamos, pois, como entender a ética no âmbito do presente trabalho.

Segundo Vásquez, "a ética é a ciência do comportamento moral dos homens em sociedade" (Vásquez, 1999: 23). Já, segundo este mesmo autor, "a moral é um conjunto de normas, aceitas livre e conscientemente, que regulam o comportamento individual e social dos homens" (idem: 63). Ou seja, a moral possui uma qualidade social. E o autor, mais adiante, acrescenta que "a função social da moral consiste na regulamentação das relações entre os homens [...] para contribuir no sentido de manter e garantir uma determinada ordem sócial" (idem: 69).

Decorre de tudo quanto precede, embora política e moral não se confundam, que ambas refletem sobre a ordem social e sobre a vida do homem em sociedade.

Segundo Vásquez, "de todas as formas de comportamento humano, o jurídico é o que mais intimamente se relaciona com a 
moral, porque os dois estão sujeitos a normas que regulam as relações dos homens" (idem: 97). Ainda segundo o autor, “a moral e o direito mudam quando muda historicamente o conteúdo de sua função social" (idem, ibidem).

A isto gostaria de acrescentar que a moral e o direito mudam ao longo dos tempos. Difícil conceber o direito e a moral como formas imutáveis. Sabe-se que as condições econômicas, sociais e políticas em que a existência do homem ocorre não se perpetuam. $\mathrm{E}$, se assim é, mudanças são esperadas no modo de interpretar a ordem social e as leis que a ordenam. Diria mesmo que é com base nessas possiveis mudanças que se pode falar em uma ética conservadora e em uma ética social, tal como faço ao longo desse trabalho, pois tampouco é possivel conceber uma ética universal. Na verdade, não há uma só ética. Há éticas que são definidas a partir de diferentes lugares sociais, de diferentes subjetividades históricas. Ou seja: éticas diversificadas e concomitantes. Entendo por ética conservadora, uma ética que percebe a lei como imutável, perpetuando para sempre os direitos conquistados pelos individuos, sem levar em conta as necessidades das demais classes sociais. Por outro lado, falo de uma ética social, para referir o questionamento feito à moral que sustenta a imutabilidade da lei e dos direitos adquiridos. Em suma, quando passa-se a falar de direitos sociais em detrimento dos direitos individuais.

\section{Encaminhando as análises}

No presente trabalho vou, pois, analisar o discurso sobre os tem-terra e não o discurso dos sem-terra propriamente dito. Segundo Mariani (1996: 64), os discursos sobre são discursos intermediários, pois ao falarem sobre um discurso, situam-se entre este e o interlocutor, qualquer que seja ele. Ainda segundo a autora, o discurso jornalistico funciona como uma modalidade de discurso sobre. 
Cabe ainda esclarecer que vou examinar tais questões basicamente à luz da noção de Formação Discursiva (também poderá ser representada por FD), tal como foi formulada por Pêcheux "aquilo que pode e deve ser dito" - e a ela vou associar a noção de ética. Nesse sentido, entendo que uma "FD pode ser concebida como um domínio de saber que regula aquilo que pode e deve ser dito por um sujeito histórico nela inscrito, contemplando tanto a dimensão política quanto a dimensão jurídica do discurso, entrelaçadas por uma visada ética”. Ou seja, estou aqui formulando uma concepção de FD, alicerçada neste lugar-fronteira em que ocorre este cruzamento de discursos e que constitui um espaço de deslizamentos de sentido, um espaço de releituras.

Neste trabalho, vou examinar duas diferentes designações que remetem à luta pela terra no Brasil: ocupação e invasão. Em trabalho anterior (Indursky, 1999), já havia examinado estas designações e seu efeitos de sentido. Diria mesmo que, no trabalho a que me refiro, foi contemplada apenas a dimensão política e semântica dessas designações. No presente trabalho, retomo essas designações para ir além, examinando-as no cruzamento do politico com o jurídico e de suas implicações éticas. Ou seja, o exame que proponho aqui conduz ao lugar-fronteira em que tais discursos se imbricam.

Para examiná-las, vou construir dois diferentes recortes discursivos. Para tanto, vou examinar algumas seqüências discursivas recortadas de matérias jornalísticas dos anos 1995-1996, publicadas na Folha de São Paulo (doravante, também pode ser F.S.P.), jornal de grande penetração nacional.

\section{A designação ocupação}

Os trabalhadores sem-terra, cansados de aguardar pela realização da reforma agrária, decidiram acelerar o processo de redis- 
tribuição das terras. Para tanto, localizam terras consideradas improdutivas para nelas instalarem seus acampamentos e darem inicio ao seu cultivo e, dessa forma, pressionar o governo a agir, desapropriando as terras ocupadas para torná-las disponiveis para posterior assentamento. Seu propósito, expresso pelo lema "ocupar, resistir, produzir", é o de acelerar o processo de Reforma Agrária, colocando o Governo face a situações, se não de direito, pelo menos, de fato. E, assim procedendo, designam sua prática de ocupação, como veremos por meio do recorte que segue.

1 - "Vamos intensificar as ocupações. É assim que vamos ajudar o governo a assentar as 40 mil famílias até o fim do ano", afirmou Rainha. (F.S.P. - 17.10.95, p. 1-11 - Matéria de George Alonso, enviado especial ao pontal do Paranapanema).

2 - A política de "ocupações”, segundo José Rainha Jr., lider do MST no Pontal do Paranapanema, não é planejada perante o dilema "terras públicas versus terras privadas". O que orienta essa política, segundo ele, é outra discussão: áreas improdutivas devem ser ocupadas enquanto houver pelo menos uma familia sem ter onde plantar. (F.S.P. - 29.10.95, p, 1-8-Matéria de Xico Sá, da reportagem local da Folha).

O recorte acima é representativo do processo de designação da tomada da terra por parte dos sem-terra. Na Formação Discursiva em que os sem-terra se inscrevem, as terras são ocupadas, é lícito mesmo fazerem-se ocupações, pois "as terras são improdutivas" ou devolutas e há familias que querem, mas não têm "onde plantar". Ou seja, trata-se de uma política dos sem-terra para acelerar as ações governamentais, amparada em uma ética social e revisionista do discurso jurídico sobre a propriedade privada e sobre o direito à terra.

Assim procedendo, promovem uma discussão que mobiliza fortemente o jurídico e está amparada numa questão de ordem ética: tem direito à terra não aquele que legalmente a possui, mas 
INDURSKY, Freda. O entrelaçamento entre o político, o jurídico e a ética no discurso...

aquele que a faz produzir ou que é capaz de fazê-la produzir. Ou seja, se a terra está improdutiva é o fazendeiro que a ocupa irregularmente. Este sentido só pode ser produzido quando alicerçado em uma releitura do jurídico à luz de uma ética conservadora. Como se vê, há uma inversão na interpretação do que é legítimo, que acaba por instaurar outro ponto de tensão nesse lugar-fronteira e que pode ser representado por dois pares de termos juridicos: legalidade X legitimidade e propriedade $\mathrm{X}$ posse. Nesse lugar-fronteira, em que os sentidos do discurso jurídico são questionados pelo viés de uma ética socialista, o legitimo se sobrepõe ao legal e a posse à propriedade. Essas novas formulações promovem deslocamentos nos sentidos já estabelecidos sobre a questão da propriedade agrária no Brasil e vão construindo o jurídico a que me referi na segunda seção deste trabalho. Como afirma Martins

\begin{abstract}
[...] Os sem-terra, na sua prática, não têm como deixar de questionar a legalidade da propriedade, não podem deixar de considerar ilegitimo [...] o que é legal, que é a possibilidade de alguém possuir mais terra do que pode trabalhar [...], nem deixar que outros utilizem, mesmo sob pagamento de renda. Se não fosse assim, não se sentiriam encorajados a ocupar a terra. (Martins, 1985: 103)
\end{abstract}

Como é possível perceber pela reflexão de Martins, está em discussão a ética que subjaz à propriedade rural, tal como ela é praticada no Brasil e, juntamente com ela, poder-se-ia mesmo dizer que está em questionamento a ética do ordenamento jurídico que permite propriedades rurais tão extensas no país, pois $1 \%$ dos proprietários rurais detêm $46 \%$ das terras brasileiras Dito em outras palavras, as propriedades rurais, do ponto de vista juridico, são consideradas legais, mas, do ponto de vista de uma ética social, ilegítimas, dando lugar à construção do jurídico e estimulando uma prática de ocupações. Ou seja, mobilizam-se aî praticas sociais - discursivas e não-discursivas. 
Essa nova postura está em pleno confronto com a posição conservadora dos proprietários rurais, os quais se apóiam em um discurso jurídico que foi produzido a partir de um determinado lugar social que se identifica com esse pensamento. Dito de outra forma, o discurso jurídico sobre a propriedade rural foi concebido por juristas que pertencem, indubitavelmente, ao mesmo lugar social dos proprietários rurais. Ou, ainda, por juristas que se identificam com a Formação Discursiva em que se inscrevem os proprietários de grandes latifúndios rurais. Ou seja, os legisladores legislam em causa própria ou em nome de seus pares, sem se preocupar com aqueles que vivem da terra, mas não a possuem, pois ela já tem um proprietário. É o que se pode perceber a partir do próximo recorte.

\section{A designação invasão}

Neste recorte, vou analisar a segunda posição-sujeito envolvida nesse processo de designação. Trata-se de designar de invasão a ocupação das terras praticada pelos sem-terra, como é possível verificar no recorte que segue.

3 - Os fazendeiros do Pontal do Paranapanema realizam hoje protesto contra as invasões de terra [...] "Não somos contra a reforma agrária. Somos contra a baderna que as invasões causam, trazendo prejuízos ao conjunto da sociedade", afirmou Célio Souza, vice-presidente do Sindicato Rural de Presidente Prudente. (F.S.P. - 27.11.95, p. 1-9)

4 - O INCRA está incentivando o desrespeito à lei e à propriedade ao permitir que os sem-terra invadam fazendas e façam exigências ao governo. A afirmação foi feita à Agência Folha em Bauru, São Paulo, pelo presidente do Sindicato Rural de Bauru e Diretor da Federação da Agricultura de São Paulo, Maurício Lima Verde Guimarães. (F.S.P. - 23.10.95, p. 1-9) 
INDURSKY, Freda. O entrelaçamento entre o político, o jurídico e a ética no discurso...

Os fazendeiros, no discurso de seus representantes, apresentam sua própria designação para a prática dos sem-terra. Essa designação diversa aponta para uma posição-sujeito igualmente diversa daquela assumida pelos sem-terra, a qual se inscreve em uma formação discursiva que lhe é antagônica. Tal antagonismo é garantido pela inscrição dessas duas $\mathrm{FD}$, a dos latifundiários e a dos sem-terra, em lugar-fronteira, vale dizer que estas duas FD se delimitam e se excluem mutuamente.

Essa diferença apóia-se igualmente no discurso jurídico e em suas implicações, ou seja, os fazendeiros protestam contra a "baderna", contra "o desrespeito à lei e à propriedade", procurando fazer valer um discurso jurídico que mantenha inalterado o direito de propriedade da terra.

Nessa formação discursiva, ignorar que a terra possui um proprietário e nela acampar mobiliza o discurso jurídico que garante o direito de propriedade (art. $5^{\circ}$ da Constituição, item XXII) e, com base nele, os latifundiários chamam os sem-terra de "invasores" e aos seus líderes de "formadores de quadrilha". Assim procedendo, ao mesmo tempo que desqualificam os sem-terra, enquanto seus interlocutores, os transformam em sujeitos fora da lei. Dito de outra forma: sujeitos de direito não dialogam com sujeitos fora da lei. Brincando um pouco mais com estes dois tipos de discurso, poderíamos falar em sujeitos dentro da lei e em sujeitos fora da lei. Eis aí, mais uma vez, o não-estabelecimento da cena de interlocução e a solidificação da interincompreensão, do lugar-fronteira.

A designação invasores, com todos os efeitos de sentido que dela provêm, está garantida por um discurso que sacraliza e imobiliza a noção de direito de propriedade, instituindo a eternização desse valor que se apresenta como absoluto e imutável e que sustenta o direito de que se arrogam os fazendeiros para se armarem para protejer sua propriedade, matando, se necessário for, seus invasores. E, quando chegam a matar (vide o julgamento do massacre dos sem-terra, em Corumbiara), nunca transpõem o limite do 
dentro da lei, pois o fazem para proteger sua propriedade, o fazem em nome da propriedade privada, apoiados no direito de propriedade. Estão, pois, apoiados na lei e dela não se afastam, não correm o risco de tornarem fora da lei.

\section{Efeitos de sentido}

Como é possivel verificar, no discurso dos sem-terra, a tomada da terra é designada de ocupação, enquanto no discurso dos proprietários rurais, a prática dos sem-terra é designada por invasão.

Essa dupla designação poderia, numa primeira visada, ser considerada pelo viés da sinonimia, pois tanto ocupação quanto invasão remetem referencialmente à prática adotada pelos semterra. Entretanto, tal não é o caso. Senão, vejamos.

Ocupação tem como referente a terra improdutiva. Invasão constrói como referente a terra privada. A primeira, por tratar da terra improdutiva, trabalha o sentido ético de uma terra que, por ser improdutiva, deve ser redistribuida para que aqueles que o desejam possam cultivá-la para dela tirar a sua subsistência e a dos seus. A segunda, por possuir um proprietário, põe em relevo o sentido jurídico de violação da propriedade privada. A primeira remete à idéia de ação pacífica exercida sobre terras abandonadas e faz ressoar um já-dito anterior, proveniente do discurso religioso da ala progressista da Igreja Católica no Brasil. Vale dizer: a pastoral da terra, as comunidades eclesiais de base e a Teologia da Libertação. A segunda traz consigo o efeito de sentido de violação da propriedade privada, ou seja, discursiviza o desrespeito à lei e faz soar o discurso jurídico sobre o direito de propriedade e a ilegalidade daqueles que adotam a prática da invasão. Como é possivel perceber, estas duas designações remetem para duas posições-sujeito 
INDURSKY, Freda. O entrelaçamento entre o político, o jurídico e a ética no discurso...

opostas, que se inscrevem em Formações Discursivas antagônicas, instaurando dois discursos que se delimitam e se excluem mutuamente, construindo aí um lugar-fronteira entre esses dizeres e saberes sobre a terra e sua posse.

Como se vê, retoma-se aqui a discussão fregeana $(1978)^{9}$ sobre sentido e referência. Ou seja, duas expressões lingüísticas diferentes (invasão/ocupação) nomeam a prática de acampar em terras que possuem um proprietário. Mas, essa dupla nomeação mobiliza saberes diferentes que se apóiam em paradigmas éticos, políticos e jurídicos diversos, dando lugar à construção de fatos políticos distintos. Essa dupla nomeação imbrica discursivamente o político, o jurídico e a ética de forma inestricável. E esse enlaçamento indissolúvel só pode reforçar ainda mais o que designo de lugar-fronteira. Dito de outra forma: somente em um lugar-fronteira é possivel mobilizar, ao mesmo tempo e de forma tão intensa, as condições de produção de duas formações discursivas antagônicas, de duas subjetividades históricas tão distintas, de saberes tão diversos.

E esse intrincamento põe em movimento uma discussão sobre os lugares políticos no Brasil. Vale dizer que as duas designações coexistem na língua, mas o uso de uma ou de outra mobiliza discursivamente sentidos diferentes que remetem a processos discursivos igualmente diferentes que se encontram em situação de coocorrência no espaço discursivo desenhado pela imprensa em seu discurso sobre o discurso do MST.

\section{A mídia e o discurso do/sobre o MST}

Essa dupla designação sinaliza, pois, duas formas-sujeito antagônicas, inscritas em Formações Discursivas em confronto que apontam para as relações de tensão que existem atualmente na cena discursiva brasileira. $E$ essa tensão vem fortemente alicerçada no discurso jurídico, tal como podemos apreciar, a partir do 
recorte que segue. As seqüências que vou analisar foram recortadas de uma matéria intitulada "MST - O filão da terra", assinada por Lourival Sant'anna e publicada na página eletrônica mantida pelo Jornal O Estado de S. Paulo (28.8.99). Nessa matéria, o articulista discute a legalidade/ilegalidade do movimento do MST, com base em uma leitura de certos artigos da Constituição. Então vejamos.

5 - "O artigo 184 da Constituição diz o seguinte: "Compete à União desapropriar por interesse social, para fins de reforma agrária, o imóvel que não esteja cumprindo sua função social". Esse é o ponto de partida legal da ação do Movimento dos Trabalhadores Sem-Terra". ${ }^{10}$

Como se percebe, o articulista, ao selecionar esse artigo da Constituição, procura, inicialmente, mostrar que a reforma agrária, pela qual propugna o MST, é legal e está prevista no texto da Lei, assentando-se sobre a despropriação para o cumprimento da "função social" da terra. Com base nisso, diria mesmo que o texto jurídico, nesse artigo, está atravessado pelo que estou chamando de ética social. Num primeiro momento, poderíamos ser levados a pensar que o articulista é favorável e se identifica com o MST. Entretanto, nada mais falso. Para melhor refletirmos, tomemos a próxima seqüência discursiva, recortada da mesma matéria do Estado de S. Paulo On line.

6 - [...] o movimento viola a Constituição noutra parte, o artigo $5^{\circ}$, em seu parágrafo 22 , segundo o qual "é garantido o direito de propriedade". ${ }^{11}$

A partir desse recorte, percebe-se que o discurso jornalístico assume a posição-sujeito dos fazendeiros, apontando a ilegalidade

\footnotetext{
9 Refiro-me aqui à edição brasileira, publicada pela Cultrix \& Edusp. O original data de 1892 .

10 O destaque é meu.

11 O destaque é meu.
} 
IndURSKY, Freda. O entrelaçamento entre o político, o jurídico e a ética no discurso...

das ações dos sem-terra, já que estes violam o "direito de proprieda$d e$ ", que está garantido em Lei, como pudemos ver pela citação que o recorte acima faz.

Mas, em sua pressa de assumir o ponto de vista dos fazendeiros, com o qual se identifica, o articulista faz uma leitura demasiado apressada e lacunar da Constitução, pois no caput do artigo $5^{\circ}$ podemos ler:

"Todos são iguais perante à lei, sem distinções de qualquer natureza, garantindo-se aos brasileiros [...] a inviolabilidade do direito "à propriedade".

Acrescente-se a isso que o teor do item XXIII desse mesmo artigo determina que

"a propriedade atenderá a sua função social".

Ou seja, a Carta Magna Brasileira se refere tanto ao direito de propriedade, em que se apóiam os fazendeiros e o articulista para designar a prática dos sem-terra de invasão, quanto ao direito à propriedade, como modo de promover a igualdade e a justiça social, ponto em que se apóiam os sem-terra para sua atividade politica de ocupações e de sua demanda pelo "direito à terra".

Estamos, pois, diante de um discurso da imprensa sobre o MST que promove uma leitura unilateral e lacunar da Constituição, aquela que salienta apenas o direito de propriedade, lugar em que o jurídico ratifica a propriedade privada, mas deixa na sombra um outro direito, o direito à propriedade, que representa o viés pelo qual o ético atravessa o jurídico, dando espaço às reinterpretações da lei à luz de uma ética social. E isso instaura o lugar em que se dá a articulação desses diferentes discursos, dessas diferentes leituras do texto constitucional. Este ponto imbrica fortemente um imaginário político e um imaginário juridico que, juntos, dão lugar a uma única interpretação do que sejam direitos legais. Isso revela indubitavelmente a visão da imprensa, fortemente identificada com 
a visão dos proprietários rurais, sobre a questão da terra no Brasil. O discurso da mídia apaga possíveis diferenças. Em sua ótica, fica apenas uma única leitura, que é dada como a leitura. E fica assim instituída a visão hegemônica sobre a problemática da terra no Brasil. Visão esta que acaba sendo repassada para o leitor da mídia como a "opinião pública". Não se pode negar que a imprensa dá visibilidade ao litígio, mas não dá para ignorar que, ao fazê-lo, o faz de um lugar identificado com o dos fazendeiros. Não dá, pois, para alegar neutralidade da imprensa, pelo menos no que tange aos conflitos sociais sobre a terra.

\section{Para encerrar}

Pois é exatamente esse segundo direito - o direito à propriedade-esquecido pelos proprietários rurais e pelo discurso midiático, que dá sustentação a releituras legais que estão na base da produção de novos sentidos com a conseqüente instauração de um novo sujeito histórico que não mais se submete passivamente à ordem jurídica estabelecida, a qual, de fato, não contempla os excluídos do processo social. Esse novo sujeito pretende ver discutida a legalidade do direito de propriedade, propugnando pela legitimidade do direito à propriedade.

Assim procedendo, esse novo sujeito emerge como sujeito político que passa a contestar a ordem jurídica, promovendo um confronto de interpretações: de um lado, encontram-se aqueles que defendem o direito de propriedade e que só vêem a questão por esse ângulo; de outro lado, encontram-se os que defendem o direito à propriedade, ou, tal como dito no discurso desse sujeito, o direito à terra, colocando em cheque a perpetuação do direito de propriedade. Para os que se identificam com o saber jurídico que perpetua a propriedade, os sem-terra praticam atos ilegais que podem ser classificados juridicamente como um "esbulho possessório" e estão 
sujeitos às penas da lei. Já os que contestam o direito de propriedade, defendendo o direito à propriedade, o direito à terra, o fazem com base em uma ética social que está embasada na péssima distribuição de terras e em uma injusta distribuição de renda, em decorrência das quais o povo passa fome. E essa não é mais uma questão puramente legal; é, a igual título, uma questão social, de subsistência. Vê-se aí, mais uma vez, a ética social atravessando o jurídico e entrelaçando-o ao político, fazendo aparecer o embate de interpretações que perpassa o discurso social do Brasil contemporâneo.

Como pode-se perceber, tal confronto se trava em um complexo lugar-fronteira: fronteira entre discursos, fronteira de posições-sujeito, fronteira de Formações Discursivas, fronteira de imaginários, fronteira de efeitos de sentido, fronteira de interesses que representam um sujeito histórico instituído há muito tempo, desde o início da colonização do Brasil pelos portugueses, e um sujeito histórico que se instituiu nas duas últimas décadas do século XX. Em suma: um lugar-fronteira entre os que sempre tiveram direito à voz e os que lutam para ver este direito reconhecido e, dessa forma, serem reconhecidos como interlocutores qualificados para partilhar de uma cena interlocutiva.

RÉSUMR: Ce travail présente l'analyse du discours (selon l'Ecole Française d'Analyse du Discours) sur/du le MST, produit aux années 95-96 par le journal Folha de S. Paulo. Les analyses tombent sur les différentes désignations à travers lesquelles est nommée la lutte par la terre au Brésil. Ces désignations identifient les différents sujets discursifs impliqués dans ce litige. Les analyses ont montré que la désignation ocupação (occupation), qui remet à la position-sujet du travailleur rural sans-terre, s'appuie $a u$ "direito à propriedade" (droit à la propriété), tandis que da désignation invasão (invasion), qui refère la position-sujet du propriétaire rural, s'appuie au "direito de propriedade" (droit de 
propriété). Cette double désignation indique que cet affrontement se donne dans un lieu-frontière où s'entrecroisent le politique, le juridique et l'éthique.

MOTS-CLE: Occupation; invasion; droit de propriété; droit à la propriété; éthique conservatrice; éthique sociale.

\section{BIBLIOGRAFIA}

Corten, A. (1999) Discurso e representação do político. In: InduRSKY, F. \& Leandro Ferreira, M. C. (Orgs.) Os múltiplos territórios da análise do discurso. Porto Alegre: Sagra-Luzzatto.

Frege, G. (1978) Lógica e filosofía da linguagem. São Paulo: Cultrix.

InDURsky, F. (1997) A fala dos quartéis e as outras vozes. Campinas: Ed. da Unicamp.

. (1999) De ocupação a invasão: efeitos de sentido no discurso do/ sobre o MST. In: Indursky, F. \& Leandro Ferreira, M. C. (Orgs.) Os múltiplos territórios da análise do discurso. Porto Alegre: Sagra-Luzzatto.

. A função enunciativa do porta-voz no discurso sobre o MST. Revista ALEA: Estudos Neolatinos, Rio de Janeiro, v. 2, n. 2, set. 2000.

Maingueneau, D. (1989) Novas tendências em análise do discurso. Trad. Freda Indursky. Campinas: Ed. da Unicamp/Pontes.

Mariani, B. S. C. (1996) O comunismo imaginário: práticas discursivas da imprensa sobre o PCB (1922-1989). Tese de Doutorado. Campinas, IEL/Unicamp.

Martins, J. S. (1985) A militarização da questão agrária no Brasil, 2. ed. Petrópolis: Vozes.

Pêcheux, M. (1988) Semântica e discurso: uma crítica à afirmação do óbvio. Campinas: Ed. da Unicamp.

. (1990) O discurso: estrutura ou acontecimento. Campinas: Pontes.

Rancière, J. (1995) La mésentente. Paris: Galilée.

VÁsguez, A. S. (1999) Ética. Rio de Janeiro: Civilização Brasileira. 